\title{
Influence of Matrix Type on Surface Roughness of Three Resins for Provisional Crowns and Fixed Partial Dentures
}

\author{
Raul Ayuso-Montero, DDS, PhD, ${ }^{1}$ Jordi Martinez-Gomis, DDS, PhD, ${ }^{1}$ Mar Lujan-Climent, DDS, ${ }^{2}$ \\ Juan Salsench, $\mathrm{MD}, \mathrm{PhD}^{3}$ \& Maria Peraire, $\mathrm{MD}, \mathrm{PhD}^{3}$ \\ ${ }^{1}$ Associate Professor, Department of Prosthodontics, Faculty of Dentistry, University of Barcelona, Spain \\ ${ }^{2}$ Research Scientist, Department of Prosthodontics, Faculty of Dentistry, University of Barcelona, Spain \\ ${ }^{3}$ Professor and Co-Chair, Department of Prosthodontics, Faculty of Dentistry, University of Barcelona, Spain
}

\section{Keywords}

Temporary crown; profilometry; matrix; fixed partial dentures.

\section{Correspondence \\ Jordi Martinez-Gomis, Faculty of Dentistry, Department of Prosthodontics, University of Barcelona, Campus de Bellvitge, C/ feixa llarga s/n L'Hospitalet de Llobregat Barcelona E-08907, Spain. E-mail: \\ jmartinezgomis@ub.edu}

Accepted December 18, 2007

doi: 10.1111/j.1532-849X.2008.00392.x

Fixed prosthodontic treatment requires indirect fabrication of definitive prostheses in the dental laboratory. Prepared teeth should be protected and stabilized with interim prostheses that resemble the definitive restoration. ${ }^{1,2}$ Polymethyl methacrylate resins, polyethyl methacrylate resins, and bis-acryl composite resins are the most used materials for interim prostheses. ${ }^{1,2}$ The major requirements for provisional materials are an appropriate marginal adaptation, resistance to fracture, low thermal conductivity, nonirritating reaction to the dental pulp and gingival tissues, and ease of cleaning. ${ }^{1,3}$ The surface of the provisional crown or fixed partial denture (FPD) should be smooth enough to be comfortable, esthetic, and able to avoid staining and plaque accumulation. In vivo studies on the threshold surface roughness for bacterial plaque retention show that a mean roughness above $0.2 \mu \mathrm{m}$ is related to a substantial increase in bacterial retention. ${ }^{4}$
In general, bis-acryl composites have been shown to be superior in occlusion, resistance to damage from dietary solvents, fracture resistance, flexural strength, contour, and marginal adaptation as compared to methacrylate resins; however, this is often material specific. ${ }^{5-9}$ The dimethacrylate-based materials have shown no significant differences in exothermic reaction during polymerization, ${ }^{10}$ but they have shown significantly lower shrinkage values from a monomethacrylate-based material. ${ }^{11}$ Although methacrylate resins have shown smoother surfaces than bis-acryl composites when polymerized without a matrix or against a plastic sheet, ${ }^{3,12}$ bis-acryl composites, compared to methacrylates, exhibit smoother surfaces when polymerized against a glass slab. ${ }^{2}$ After polishing, methacrylate resins have demonstrated smoother surfaces than bis-acryl composite. ${ }^{3,12-14}$ Therefore, there is no ideal provisional material suitable for all clinical conditions. ${ }^{3}$ 
Table 1 Resins for provisional restorations tested and matrices used

\begin{tabular}{|c|c|c|}
\hline Product & Resin/matrix-type & Manufacturer \\
\hline \multicolumn{3}{|l|}{ Resins } \\
\hline Trim II & Polyethyl methacrylate & $\begin{array}{l}\text { Bosworth Company } \\
\text { Skokie, IL }\end{array}$ \\
\hline TAB 2000 & Polymethyl methacrylate & Kerr, Salerno, Italy \\
\hline Protemp II Garant & Bis-acryl composite & ESPE, Norristown, PA \\
\hline \multicolumn{3}{|l|}{ Matrices } \\
\hline Cavex CA37 & Irreversible hydrocolloid & $\begin{array}{c}\text { Cavex Holland BV, } \\
\text { Haarlem, The } \\
\text { Netherlands }\end{array}$ \\
\hline Aquasil Soft Putty & Poly(vinyl siloxane) & $\begin{array}{l}\text { Dentsply Detrey, } \\
\text { Konstanz, Germany }\end{array}$ \\
\hline Bio-flow Hard & Vacuum-formed matrix & Dreve, Unna, Germany \\
\hline
\end{tabular}

Interim crowns and FPDs are generally fabricated using a custom-made technique or using preformed materials. Both procedures can be accomplished with direct clinical, indirect laboratory, or direct/indirect combination techniques. ${ }^{1}$ The custom fabrication technique represents one of the best choices for interim prosthetic treatment, and the intraoral autopolymerizing method is the one most frequently used. ${ }^{1}$ Impression materials (irreversible hydrocolloid [15] and poly(vinyl siloxane) [13]) and a vacuum-formed shell of a dental cast ${ }^{16}$ are very common and useful matrices for direct fabrication of interim crowns and FPDs. Irreversible hydrocolloid is cheaper than poly(vinyl siloxanes) and vacuum-formed materials; however, irreversible hydrocolloid has demonstrated accuracy at 1 hour after impression, but not at 24 hours, due to evaporation. ${ }^{15}$ The main advantage of poly(vinyl siloxane) and a vacuum-formed shell is a long-term dimensional stability.

The surface roughness of various interim resins has been evaluated in a range of conditions, ${ }^{2,3,12-14}$ but the effect of the matrix type has not been taken into account. Here, we evaluate the effect of matrix type on the surface roughness of three resins used to make interim crowns and FPDs by the custom fabrication technique.

\section{Materials and Methods}

Three resins were evaluated using three matrices as shown in Table 1. One natural maxillary central incisor was used as control and was embedded in a polytetrafluoroethylene box (5.5 cm long, $3.5 \mathrm{~cm}$ wide, $1.0 \mathrm{~cm}$ deep) with stone (Durodon, Odoncia, Ivry-sur-Seine Cedex, France) exposing the vestibular face. Three lids of this box were used as trays for the three matrices (Fig 1). The first lid was filled with irreversible hydrocolloid
(CA37, Cavex Holland BV, Haarlem, The Netherlands) and was applied against the vestibular face of the central incisor under a $1 \mathrm{~kg}$ weight simulating the preoperative impression of the tooth and used as the irreversible hydrocolloid matrix. Following the same procedure, the second lid was filled with poly(vinyl siloxane) (Aquasil Soft Putty, Dentsply Detrey, Konstanz, Germany) and was used as the poly(vinyl siloxane) matrix. The third lid was filled with irreversible hydrocolloid and poured in stone, and the thermoplastic material (Bio-flow Hard, Dreve, Unna, Germany) was vacuum-adapted to this stone cast to fabricate the vacuum-formed matrix. All materials were manipulated according to the manufacturers' instructions.

To obtain a 2-mm thickness for the provisional specimens, a 2-mm high ring of stone (Durodon) was placed around the external part of the tooth inside the box. Ninety interim prostheses were obtained by filling 10 specimens of each matrix with each of the three acrylic resins, that is, the sample size for each resin-matrix combination was 10 . The trays were filled by putting the resin in excess into the matrices and then replacing the matrix lid on the box under a $1 \mathrm{~kg}$ weight to extrude excess material. The resin was then allowed to polymerize (Fig 2). All specimens were coded, and analyses were performed blind by a single operator who was not calibrated.

The surface topography of the specimens and the surface of the natural incisor were measured by means of a surface roughness tester (Surftest 301, Mitutoyo, Aurora, IL). All recordings were made as close as possible to the specimen center using a custom-made "positioner." Three scans (4.0-mm length, velocity $0.5 \mathrm{~mm} / \mathrm{s}$, force $4 \mathrm{mN}$, radius of curvature $5 \mu \mathrm{m}$ ) were made for each of the 90 specimens and the tooth. The average roughness $(\mathrm{Ra})$ of each specimen was determined, that is, the average height (in $\mu \mathrm{m}$ ) of the profile above and below a central line. The surface roughness tester was calibrated, and the diamond point was cleaned after every 15 scans following the manufacturer's recommendations. Kruskal-Wallis and Mann-Whitney $U$-tests were used to compare the groups. The results were contrasted against the surface roughness of the tooth using a one-sample $t$-test $(p<0.05$ was significant).

\section{Results}

The average surface roughness of the tooth was $0.41 \mu \mathrm{m}$ (SD 0.02 ). The average surface roughness of the resin specimens polymerized against the three matrices is shown in Figure 3. Mean Ra values (in $\mu \mathrm{m}$ ) ranged from 0.56 to $0.70,1.26$ to 2.42, and 1.35 to $2.48 \mu \mathrm{m}$ for Protemp II Garant, Tab 2000, and Trim II, respectively. Protemp II Garant specimens gave the smoothest surface regardless of the matrix used, with no significant differences when polymerized against the three different
Figure 1 Natural maxillary incisor (A) and the three matrices, Cavex CA37 (B), Aquasil (C), vacuum-formed matrix (D).
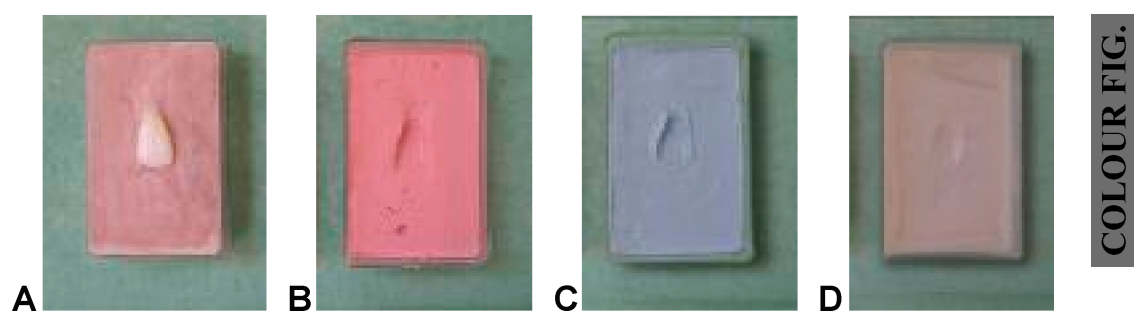
Figure 2 Fabrication of the 2-mm thickness of interim prosthesis specimens $(A)$ under $1 \mathrm{~kg}$ weight (B).

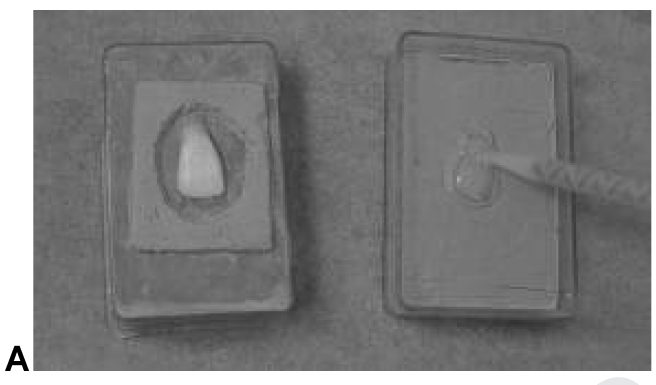

matrices. The vacuum-formed matrix gave a smoother $(p<$ 0.05) surface than Cavex CA37, when testing Trim II and Tab 2000. Trim II, in combination with Cavex CA37, gave a rougher $(p<0.05)$ surface than Trim II with Aquasil or the vacuum-formed matrix. Tab 2000 specimens gave a significantly smoother surface $(p<0.05)$ when polymerized against a vacuum-formed matrix, as compared to when this resin was used in combination with Cavex CA37 or Aquasil (between which there were no significant differences).

Protemp II Garant polymerized against the Cavex CA37 matrix was found to be the only combination with a surface not significantly rougher than the tooth surface $(p>0.05)$.

\section{Discussion}

The results indicate that any of the three matrices studied is capable of conferring the smoothest surface to the three resins used. The quality of the surface depends on the interaction between the matrix and the resin, because physical and chemical characteristics of the materials influence each other. ${ }^{15,17}$

The best surface roughness was found with a resin composite material (Protemp II Garant) regardless of the matrix used (Ra

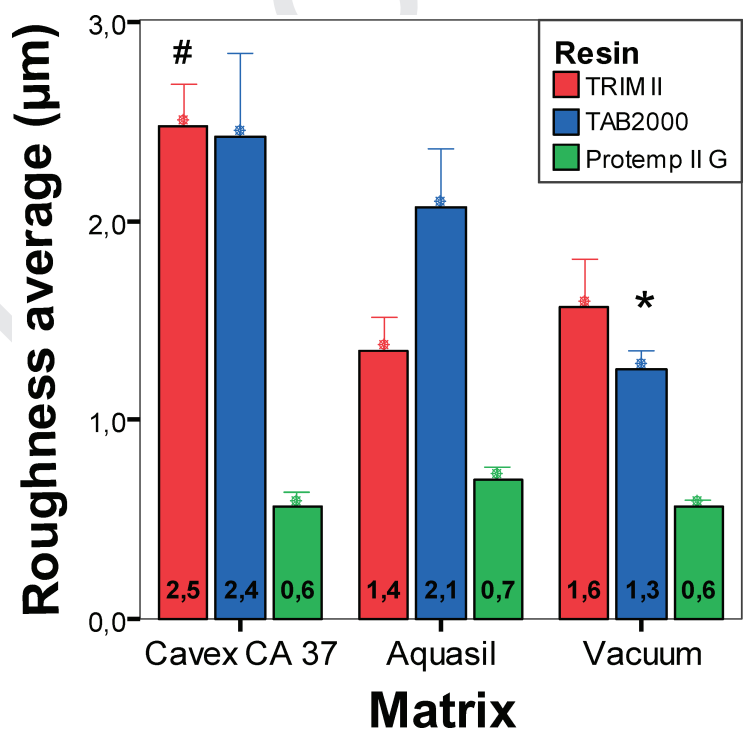

Figure 3 Mean of average surface roughness of the resins set against the different matrices. Error bars are standard error of means. $\# p<0.05$ with respect to Aquasil or Vacuum, $* p<0.05$ with respect to Cavex CA37 or Aquasil. (Mann-Whitney $U$-test), $n=10$. values ranged from $0.56 \mu \mathrm{m}$ to $0.70 \mu \mathrm{m})$. Protemp II Garant polymerized against the irreversible hydrocolloid matrix gave a surface that was not significantly rougher than the surface of the tooth. Taking into account that unfinished composite materials are smoother than finished or polished ones, ${ }^{2,18}$ Protemp polymerized against a Cavex CA37 matrix gave a surface smooth enough to make polishing unnecessary. In contrast, methacrylate resins demonstrated a high surface roughness compared to the bis-acryl composite, as found by other authors. ${ }^{2,13}$ Therefore, these materials should be polished for esthetic reasons and to prevent plaque accumulation. Rougher intraoral surfaces accumulate and retain more plaque, and so they are more frequently surrounded by an inflamed periodontium. ${ }^{4}$

The aim of the present study was to evaluate the surface roughness of the resins immediately after fabrication. Therefore, the results cannot be directly extrapolated to long-term clinical use of provisional crowns and FPDs, since factors like dietary habits ${ }^{13}$ or toothbrushing ${ }^{18,19}$ can influence surface roughness of restorative materials. Further clinical research is needed to elucidate the influence of the matrix type on the quantity or quality of plaque accumulation due to provisional crowns and FPDs.

The surface roughness of the specimens made with Trim II and Tab 2000 depends on the matrix used, but there are no differences when the specimens are made with Protemp II Garant. Irreversible hydrocolloid is cheaper than poly(vinyl siloxanes) and vacuum-formed materials. Irreversible hydrocolloid demonstrated accuracy at 1 hour after impression, but not at 24 hours due to its evaporation properties. ${ }^{15}$ In this study, Trim polymerized against Aquasil showed a smoother surface than that against Cavex CA37. The main advantage of poly(vinyl siloxane) is its long-term stability, ${ }^{13}$ and it is useful for long working time. ${ }^{15}$ Vacuum-formed material is stable, ${ }^{16}$ and its main advantage is that it allows visualization of the material, thereby avoiding the introduction of voids. ${ }^{20}$

The method used in the present study mimicked the clinical procedure of making a provisional crown by direct fabrication, which entails a departure from enamel, with a rough surface $(\mathrm{Ra}=0.41 \mu \mathrm{m})$, similar to that reported by other authors. ${ }^{21}$ Therefore, it is difficult to compare the results with those furnished by other authors, because in other studies the resins were polymerized against other materials ${ }^{2,12}$ or were polished..$^{2,3,12-14}$ In the present study, the matrix type did not significantly affect the surface roughness of Protemp II Garant. Surface roughness of methacrylate resins (Trim II and Tab2000) seems to depend on the matrix type used. Values for methacrylate resins ranged from $1.3 \mu \mathrm{m}$ to $2.5 \mu \mathrm{m}$, higher than the 
$0.6 \mu \mathrm{m}$ reported by other authors who set these resins against a plastic sheet or glass slab. ${ }^{2,3}$

\section{Conclusion}

There is no universal matrix that produces the smoothest surface on each of the three resins studied. Protemp II Garant polymerized against Cavex CA37 matrix yields a surface that is smooth enough not to require polishing unless this surface is adjusted.

\section{References}

1. Burns DR, Beck DA, Nelson SK: A review of selected dental literature on contemporary provisional fixed prosthodontic treatment: report of the Committee on Research in Fixed Prosthodontics of the Academy of Fixed Prosthodontics. J Prosthet Dent 2003;90:474-497

2. Maalhagh-Fard A, Wagner WC, Pink FE, et al: Evaluation of surface finish and polish of eight provisional restorative materials using acrylic bur and abrasive disk with and without pumice. Oper Dent 2003;28:734-739

3. Wang RL, Moore BK, Goodacre CJ, et al: A comparison of resins for fabricating provisional fixed restorations. Int $\mathbf{J}$ Prosthodont 1989;2:173-184

4. Bollen CM, Lambrechts P, Quirynen M: Comparison of surface roughness of oral hard materials to the threshold surface roughness for bacterial plaque retention: a review of the literature. Dent Mater 1997;13:258-269

5. Young HM, Smith CT, Morton D: Comparative in vitro evaluation of two provisional restorative materials. J Prosthet Dent 2001;85:129-132

6. Yap AU, Mah MK, Lye CP, et al: Influence of dietary simulating solvents on the hardness of provisional restorative materials. Dent Mater 2004;20:370-376

7. Haselton DR, Diaz-Arnold AM, Vargas MA: Flexural strength of provisional crown and fixed partial denture resins. J Prosthet Dent 2002;87:225-228

8. Lang R, Rosentritt M, Behr M, et al: Fracture resistance of
PMMA and resin matrix composite-based interim FPD materials. Int J Prosthodont 2003;16:381-384

9. Scherrer SS, Wiskott AH, Coto-Hunziker V, et al: Monotonic flexure and fatigue strength of composites for provisional and definitive restorations. J Prosthet Dent 2003;89:579-588

10. Kim SH, Watts DC: Exotherm behavior of the polymer-based provisional crown and fixed partial denture materials. Dent Mater 2004;20:383-387

11. Kim SH, Watts DC: Polymerization shrinkage-strain kinetics of temporary crown and bridge materials. Dent Mater 2004;20:88-95

12. Sen D, Goller G, Issever H: The effect of two polishing pastes on the surface roughness of bis-acryl composite and methacrylate-based resins. J Prosthet Dent 2002;88:527-532

13. Haselton DR, Diaz-Arnold AM, Dawson DV: Effect of storage solution on surface roughness of provisional crown and fixed partial denture materials. J Prosthodont 2004;13:227-232

14. Borchers L, Tavassol F, Tschernitschek H: Surface quality achieved by polishing and by varnishing of temporary crown and fixed partial denture resins. J Prosthet Dent 1999;82:550-556

15. Chen SY, Liang WM, Chen FN: Factors affecting the accuracy of elastometric impression materials. J Dent 2004;32:603-609

16. Luthardt RG, Stossel M, Hinz M, et al: Clinical performance and periodontal outcome of temporary crowns and fixed partial dentures: a randomized clinical trial. J Prosthet Dent 2000;83:32-39

17. Murata H, Kawamura M, Hamada T, et al: Physical properties and compatibility with dental stones of current alginate impression materials. J Oral Rehabil 2004;31:1115-1122

18. Yap AU, Wu SS, Chelvan S, et al: Effect of hygiene maintenance procedures on surface roughness of composite restoratives. Oper Dent 2005;30:99-104

19. Neme AM, Wagner WC, Pink FE, et al: The effect of prophylactic polishing pastes and toothbrushing on the surface roughness of resin composite materials in vitro. Oper Dent 2003;28:808-815

20. Dunn WJ, Davis JT, Casey JA: Polytetrafluoroethylene (PTFE) tape as a matrix in operative dentistry. Oper Dent 2004;29:470-472

21. Heintze SD, Forjanic M: Surface roughness of different dental materials before and after simulated toothbrushing in vitro. Oper Dent 2005;30:617-626 